\title{
Research on Spatio-Temporal Characteristics and Obstacle Diagnosis of Ecosystem Security in Huaihe River Economic Belt
}

\author{
Yanna Zhu ${ }^{1,2 *}$, Gang He ${ }^{1,2 * *}$, Guisheng Zhang ${ }^{1}$, Xiangqian Wang ${ }^{2}$, Chaoyu Yang ${ }^{2}$ \\ ${ }^{1}$ State Key Laboratory of Mining Response and Disaster Prevention and Control in Deep Coal Mines, \\ Huainan, Anhui, 232001, China \\ ${ }^{2}$ College of Economy and Management, Anhui University of Science and Technology, Huainan, Anhui, 232001, China \\ Address: No.168, Taifeng Street, Huainan, Anhui province, China
}

Received: 12 December 2020

Accepted: 8 April 2021

\begin{abstract}
The security pattern of the ecosystem in Huaihe River Economic Belt plays a vital role in maintaining the healthy and stable structure of the ecosystem and the green development of the ecological environment in the central and eastern regions of China. This study takes Anhui section of Huaihe River Economic Belt as the case studies, and then the Pressure-State-Response (PSR) theory was used to construct the ecosystem security evaluation index system. In addition, cloud matter element as well as resistance diagnosis model was adopted to dynamically evaluate the spatio-temporal evolution pattern. The final stage was to diagnose main obstacle factors of ecosystem security in Anhui section of Huaihe River Economic Belt from 2010 to 2018. The results indicate that: (1) Overall, the ecosystem security level of Anhui section of the Huaihe River Economic belt has undergone the evolution trend of "descending - ascending - descending - ascending", and the overall change shows the curve of "W" shape. (2) From the perspective of spatial evolution, the ecosystem security level of southern cities is higher than that of northern cities. (3) The main obstacle factors are urban population density, the proportion of energy conservation and environmental protection expenditure in fiscal expenditure, per capita urban road area, and industrial wastewater discharge, etc. Therefore, according to the regional development differentiation strategy, it is necessary to actively advocate the development mechanism of banning new construction, closing pollution sources, and optimizing structure as well as building new green, so as to further promote the safe and healthy operation of the ecosystem in Anhui section of the Huaihe River Economic Belt.
\end{abstract}

Keywords: ecosystem security, obstacle factor, spatial and temporal patterns, resistance diagnostic model, Huaihe River Economic Belt

*e-mail: ynzhu001@163.com

**e-mail: 571436747@qq.com 


\section{Introduction}

The report to the $19^{\text {th }}$ National Congress of the Communist Party of China (CPC) clearly points out that the construction of ecological civilization is a "millennium plan" for the sustainable development of the Chinese nation. The report proposes that we must adhere to the basic national policy of resource conservation and environmental protection. Meanwhile, the strictest ecological environment protection system will be implemented [1]. From December 10 to December 12, 2019, Xi Jinping delivered an important speech at the central economic work conference. He stressed that we should firmly fight the battle of pollution prevention and control, so as to promote the continuous improvement of ecological environment quality [2]. In March 2020, Ministry of Ecology and Environment of the People's Republic of China issued the document "Guidance on overall planning for epidemic prevention and control, economic and social development, ecological and environmental protection work". The document emphasizes, on the one hand, we should focus on accurate, scientific and legal pollution control, and focus on solving outstanding problems. On the other hand, we should continue to improve the quality of the ecological environment and ensure the safety of the ecological environment [3]. Obviously, the strategic position of ecological civilization construction is rising day by day. As an important part of national ecological environment, it is very important to comprehensively evaluate the ecological security of ecosystem, and dynamically monitor the development trend of ecosystem security level. It is also of great significance to improve the ecological environment, resolve ecological risks and promote the national ecological environment protection work.

At present, scholars at home and abroad have conducted research and evaluation on ecosystem security from different perspectives. Thomas constructed an index system from the aspects of ecological environmental factors to evaluate the ecological security of land [4]. Whitford cooperated with rapport to construct the index evaluation system of ecosystem from the aspect of ecosystem restoration function, and carried out ecological security assessment [5]. Zhang et al. Integrated the ecosystem service flows model into water security assessment to simulate the spatial patterns of water security in Weihe River Basin (WRB) from 2005 to 2015 [6]. Based on ecological security, Chen discussed the optimization of land cover pattern using remote sensing data [7]. By using catastrophe model, De Lange carried out relevant research on land ecological risk assessment [8]. Malczewski used spatial model to study the change of ecological security status in different numerical ranges [9]. Barnhouse proposed and established an evaluation model suitable for ecological risk management from two research scales of region and individual [10]. Based on the brittle structure model and set pair theory, Lai and
Xiao considered Chengdu city and Sichuan Province as case studies to firstly explored the main research methods of urban ecological security theory and its characteristics, then conducted a theory of complex system brittleness to analyze the urban ecological security brittle factors, brittle primitives, and brittle structure. The theoretical and empirical analysis showed that the brittle correlation entropy of natural subsystem in urban ecological security is the biggest one [11]. In relation to the actual socio-economic development of the Guanzhong Plain urban agglomeration (GPUA), Yang and Cai added three sub-accounts covering domestic water, production water and eco-environment water to the adapted ecological footprint model to reflect the underestimated water demand in the GPUA. Based on an analysis of the per capita ecological deficit and the dynamic changes in each account in the GPUA from 2005 to 2017, the ecological pressure index and eco-economic coordination index were used to evaluate the ecological security level of GPUA, and the footprint depth and footprint size were used to evaluate trends in the state of ecological security [12].

By building a comprehensive disaster index, $\mathrm{Li}$ studied the risk of drought, flood and soil erosion on Vegetation Ecosystem in Shiyang River Basin [13]. Taking drought and flood as risk sources, Wang used the relative risk model to study the ecological security status of Lijiang River Basin from three aspects: risk source, vulnerability and anti risk ability [14]. Gong selected landscape fragmentation, landscape separation and landscape dominance as indicators to measure the response degree of different land use types to human activities, and constructed a comprehensive index of watershed ecosystem to evaluate the ecological risks brought by human activities to Bailong River Basin [15]. With the help of the methods of ecosystem sensitivity analysis and hot spot analysis, Song evaluated the ecosystem security pattern composed of six important ecological patches, 10 River corridors, 2 biological channels and 26 stepping stone corridors in Qinba Mountain Area [16]. Jiang used the obstacle diagnosis model and Least Square Estimate (LSE) method to analyze the security of the land use system in China section of the "Silk Road Economic Belt" and divided the resistance types [17]. Taking the Yellow River Basin as the research object, firstly, Jin discriminated the main limiting factors of ecological protection and highquality development in the Yellow River Basin. Then, she analyzed the stress characteristics of industrial development on the ecological environment. Finally, the optimization path is proposed for the existing problems [18]. Sun et al. believed that maintaining optimal ecological security is a serious issue in the Chinese Loess Plateau (CLP). Remote sensing ecological indexes (RSEI) of three main tableland regions of the CLP were calculated based on spectral information provided by remote sensing imaging satellites between 2000 and 2018 [19]. 
To sum up, in the light of recent relative literature, most of the existing literatures adopted quantitative methods to study the regional ecological environment security assessment, which have been relatively useful. However, there was a lack of research involving the fuzzy and random problems in the evaluation process. Moreover, the systematic and dynamic evaluation of ecological system security was also insufficient. Based on traditional evaluation models and related literature, combined with the characteristics of ecosystem security in Huaihe River Economic Belt, this study selects eight cities in Anhui Province as the case studies. Firstly, this paper adopts variable weight and cloud matterelement model to measure the ecosystem security status of Anhui section of Huaihe River Economic Belt, to analyze the evolution characteristics of its time sequence, and to grasp the system structure from the essence. Secondly, ArcGIS software is used to visualize the spatial distribution of ecosystem security level in Anhui section of Huaihe River Economic Belt. Finally, the ecological obstacle factors of ecosystem security level in the study area are diagnosed by using the obstacle degree model. This study can provide a theoretical basis for the comprehensive management of resources and environment in Anhui section of Huaihe ecological economic belt, and also provide a reference for regional ecosystem security assessment.

\section{Materials and Methods}

\section{Study Area}

The Anhui section of Huaihe River Economic Belt includes eight cities: Huaibei, Bozhou, Suzhou, Bengbu, Fuyang, Huainan, Chuzhou and Lu'an. As shown in Fig. 1, Anhui Province, located in the interior of eastern China, is a crucial energy base of Yangtze River Delta economic zone [20], a link between eastern and western regions, and a region carrying on industrial transfer from the developed coastal areas [21].
In 2018, the land area of Anhui Province was about sixty-seven thousand square kilometers, accounting for $25 \%$ of the total land area of Huaihe River Economic Belt. Focusing on the current situation of ecosystem security in Anhui section of Huaihe River Economic Belt, it is found that the regional ecosystem is facing many threats now. Therefore, in order to respond to the concept of ecological civilization construction, it is urgent to renovate the ecological environment system in Anhui section of Huaihe River Economic Belt. How to evaluate and improve the regional ecosystem security is related to the sustainable development of the ecological environment in northern and central Anhui, and also provides reference for the ecological protection of the whole Huaihe River Economic Belt.

\section{Data Sources}

Considering the real-time, consistency and availability of the research data, the original data required for this study are all from the statistical yearbook of Anhui Province (2011-2019), the china statistical yearbook (2011-2019) and the china statistical bulletin (2010-2018) of eight cities in the Anhui section of the Huaihe River Economic Belt. What's more, the official website of the Environmental Protection Bureau is also contained, etc. [22-24].

\section{Research Method}

\section{Cloud Matter-Element Model}

The matter-element model is composed of the name $N$, the feature $c$ and the value $v$ corresponding to the feature. An ordered triple is used as the basic element to describe the object, which is marked as $R=(N, c, v)$ [25]. Among them, $v$ represents the boundary value or measured value of each indicator, and is a certain data value. In fact, $v$ may be uncertain or have a relatively stable range, which is fuzzy and random. Therefore, this paper introduces the cloud model into the matter-

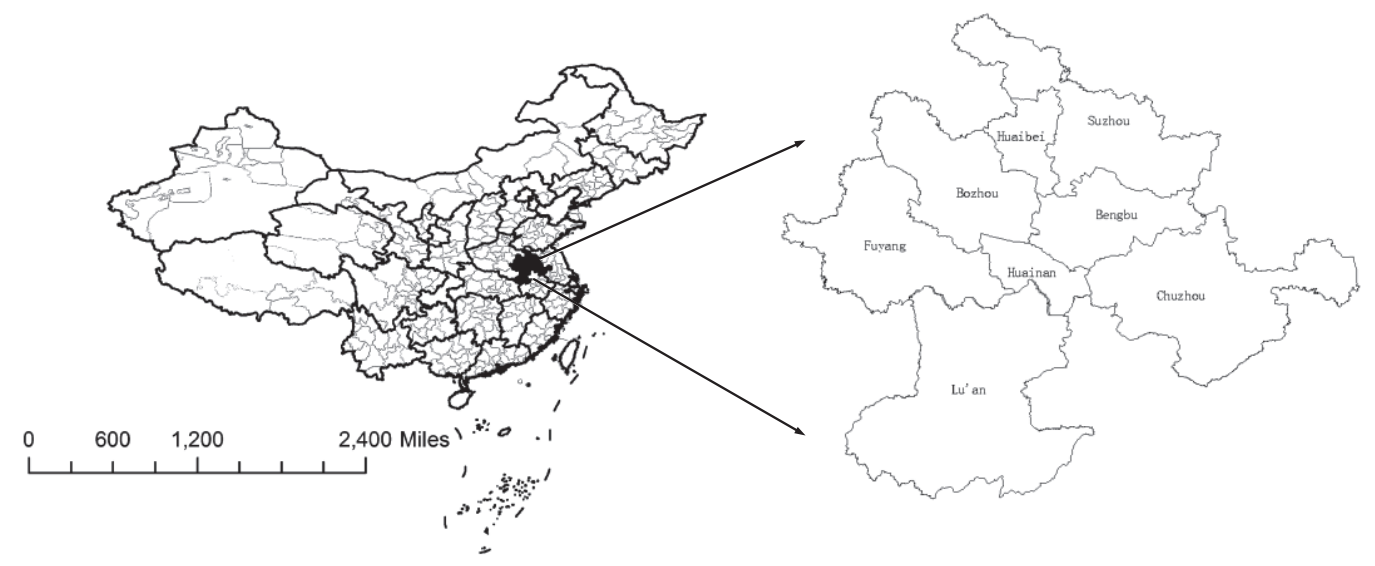

Fig.1. Location map of Anhui Section of HuaiHe River Economic Belt. 
element model, which can eliminate the double uncertainty of things. The cloud matter-element model is constructed to make up for the deficiency of the matter-element model [26]. The specific steps are as follows:

In the first step, the paper constructs the $n$-dimensional cloud matter-element matrix. If a thing $N$ is described by $n$ features $\mathrm{C}_{1}, \mathrm{C}_{2}, \ldots, \mathrm{C}_{n}$ and their corresponding quantitative values $v_{1}, v_{2}, \ldots, v_{n}$, then its $n$-dimensional matter-element matrix is as follows:

$$
R=\left[\begin{array}{ccc}
N & C_{1} & v_{1} \\
& C_{2} & v_{2} \\
& \cdots & \cdots \\
& C_{n} & v_{n}
\end{array}\right]
$$

The value $v$ corresponding to the feature is replaced by a normal cloud $\left(E_{x}, E_{n}, H_{e}\right)$ to obtain an $n$-dimensional cloud matter-element matrix.

$$
R_{\text {cloud }}=\left[\begin{array}{ccccc}
N & C_{1} & \left(E_{x 1},\right. & E_{n 1}, & \left.H_{e 1}\right) \\
& C_{2} & \left(E_{x 2},\right. & E_{n 2}, & \left.H_{e 2}\right) \\
& \ldots & \ldots & \ldots & \ldots \\
& C_{n} & \left(E_{x n},\right. & E_{n n}, & \left.H_{e n}\right)
\end{array}\right]
$$

In the second step, the standard cloud matterelement is determined, which is similar to the classical domain in matter-element model.

$$
R_{0 j}=\left[\begin{array}{ccccc}
M_{j} & C_{1} & \left(E_{x 1},\right. & E_{n 1}, & \left.H_{e 1}\right) \\
& C_{2} & \left(E_{x 2},\right. & E_{n 2}, & \left.H_{e 2}\right) \\
& \ldots & \ldots & \ldots & \ldots \\
& C_{n} & \left(E_{x n},\right. & E_{n n}, & \left.H_{e n}\right)
\end{array}\right]
$$

In formula (3), $R_{0 j}$ indicates the evaluation level $j$ $(j=1, \ldots, m) ; M_{j}$ is the standard object under the evaluation grade $j ; C_{i}$ is the evaluation index $(i=1, \ldots, n) ;\left(E_{x i}, E_{n i}, H_{e i}\right)$ is the standard cloud model of $R_{0 j}$ about $C_{i}$.

In the third step, it is necessary to determine the characteristic matter-element model $R_{0}$ of the object $P$ to be evaluated:

$$
R_{0}=\left[\begin{array}{ccc}
P & C_{1} & v_{1} \\
& C_{2} & v_{2} \\
& \cdots & \cdots \\
& C_{n} & v_{n}
\end{array}\right]
$$

In the fourth step, it is essential to determine the cloud matter-element correlation function and correlation degree. According to the characteristics of urban ecological security assessment, the correlation degree is calculated according to the correlation function.

Firstly, the determined index value $x$ is regarded as a cloud drop. Secondly, a normal random number $E_{n}$ ' with expected value $E_{n}$ and standard deviation $H_{e}$ is generated. Thirdly, the correlation degree $K$ between the numerical value $x$ and the normal cloud matter-element is calculated. The formula is shown in formula (5).

$$
k=\exp \left(-\frac{\left(x-E_{X}\right)^{2}}{2\left(E_{n}^{\prime}\right)^{2}}\right)
$$

The correlation degree calculation method of the criterion layer is shown in Formula (6).

$$
k_{m j}\left(P_{m}\right)=\sum_{i=1}^{n} \omega_{i j} k_{j}\left(v_{i}\right)
$$

In formula (6), $k_{m j}\left(P_{m}\right)$ is the correlation degree of the $i$-th criterion layer about the evaluation grade $j ; k_{j}\left(v_{i}\right)$ is the correlation degree of $v_{i}$ index in the $\mathrm{i}$-th criterion layer with respect to the evaluation grade $j ; w_{i j}$ is the corresponding index weight.

The comprehensive correlation degree is calculated as formula (7).

$$
k_{m}\left(P_{m}\right)=\sum_{i=1}^{n} \omega_{i} k_{\dot{m}}\left(P_{m}\right)
$$

Formula (7) represents the correlation degree of object $P$ with respect to grade $j$. The determination of evaluation grade follows the principle of maximum membership. If $k_{j}=\max k_{j}(P)$, the evaluation grade of $P$ to be evaluated is $j$.

\section{Resistance Diagnostic Model}

In the process of regional ecosystem security assessment, it is not only necessary to assess the regional ecosystem security, but also important to find the obstacle factors that affect the ecosystem security, so as to formulate and adjust the regional ecological environmental protection policies. Hence, in this paper, the resistance diagnosis model is introduced into regional ecosystem security assessment to further carry out pathological diagnosis of regional ecosystem security [27-28]. The calculation formula is as follows:

$$
\begin{gathered}
F_{j}=W_{r} \cdot W_{j} ; \quad I_{i j}=1-v_{i j} \\
y_{i j}=\left(F_{j} \cdot I_{i j} / \sum_{j=1}^{n} F_{j} \cdot I_{i j}\right) \cdot 100 \% \\
Y_{r}=\sum y_{j}
\end{gathered}
$$

In formula (8), $F_{j}$ is the factor contribution degree, which indicates the influence degree of single index on the overall goal; $I_{i j}$ is the index deviation degree, which indicates the difference between the evaluation value 
of a single index and $100 \%$. In formula (9) and (10), $y_{i j}$ and $Y_{r}$ are the resistance values of single index and each criterion layer index, which are the goal and result of resistance diagnosis. $v_{i j}$ is the standardized value of each index, $W_{j}$ represents the weight of a single indicator, and $W_{r}$ represents the weight of the criterion layer to which the indicator belongs. According to the ranking of $y_{i j}$ and $Y_{r}$, the primary and secondary relationship of obstacle factors and the strength of resistance value of regional ecosystem security index layer and criterion layer can be determined respectively.

\section{Index System}

Based on the research results of relevant scholars, this paper classifies the multi-dimensional factors involved in ecosystem security research of Huaihe River Economic Belt into PSR model and NaturalEconomic-Social (NES) analysis framework. The PSR model emphasizes the causal and logical relationship between the evaluation objectives and the influencing factors, and has a strong systematic character [29]. The NES model covers three subsystems: natural, economic, and social, and selects index data of different properties from the subsystems to reflect the attribution, complexity, and systematicness of the evaluation objectives [30]. In this paper, the combination of subjective and objective weighting method was used to obtain the weight coefficient between each index, among which the subjective weight accounted for $40 \%$ and the objective weight accounted for $60 \%$. The index system and weight of ecosystem security is listed in Table 1.

\section{Results and Discussion}

\section{Comprehensive Analysis of Ecosystem Security Assessment Results}

According to the calculation formula of cloud matter-element model grade correlation degree (6) and (7), the comprehensive and the criterion layer ecosystem security grade correlation degree in Anhui section of Huaihe River Economic Belt from 2010 to 2018 were calculated respectively. On the one hand, in accordance with the principle of maximum membership degree and the classification standard of ecosystem security [31], on

Table 1. Evaluation index system and weight of ecosystem security.

\begin{tabular}{|c|c|c|c|c|c|c|c|}
\hline Target layer & $\begin{array}{c}\text { Criterion } \\
\text { layer }\end{array}$ & $\begin{array}{l}\text { Factor } \\
\text { layer }\end{array}$ & Index layer & $\begin{array}{c}\text { Index } \\
\text { properties }\end{array}$ & $\begin{array}{c}\text { AHP } \\
\text { weight }\end{array}$ & $\begin{array}{l}\text { Entropy } \\
\text { weight }\end{array}$ & $\begin{array}{c}\text { Comprehensive } \\
\text { weight }\end{array}$ \\
\hline \multirow{15}{*}{$\begin{array}{c}\text { Evaluation } \\
\text { index system } \\
\text { of ecosystem } \\
\text { security in } \\
\text { Anhui } \\
\text { section of } \\
\text { Huaihe River } \\
\text { Economic } \\
\text { Belt }\end{array}$} & \multirow{15}{*}{$\begin{array}{c}\text { Pressure } \\
(\mathrm{P})\end{array}$} & \multirow{6}{*}{$\begin{array}{l}\text { Natural } \\
\text { pressure }\end{array}$} & $\mathrm{X}_{1}$ Natural population growth rate $(\% \mathrm{o})$ & - & 0.057 & 0.021 & 0.035 \\
\hline & & & $\begin{array}{l}\mathrm{X}_{2} \text { Daily domestic water consumption per } \\
\text { capita }(\mathrm{L} / \text { person } \cdot \text { day })\end{array}$ & - & 0.024 & 0.022 & 0.023 \\
\hline & & & $\begin{array}{l}\mathrm{X}_{3} \text { Electricity consumption of the whole } \\
\text { society }(100 \text { million } \mathrm{KW} \cdot \mathrm{h})\end{array}$ & - & 0.053 & 0.022 & 0.034 \\
\hline & & & $\begin{array}{l}\mathrm{X}_{4} \text { Fertilizer application rate per unit } \\
\text { cultivated area }\left(\mathrm{kg} / \mathrm{hm}^{2}\right)\end{array}$ & - & 0.073 & 0.036 & 0.051 \\
\hline & & & $\begin{array}{l}X_{5} \text { Pesticide application rate per unit } \\
\text { cultivated area }\left(\mathrm{kg} / \mathrm{hm}^{2}\right)\end{array}$ & - & 0.029 & 0.033 & 0.031 \\
\hline & & & $\begin{array}{l}\mathrm{X}_{6} \text { Amount of plastic film used per unit } \\
\text { cultivated area }\left(\mathrm{kg} / \mathrm{hm}^{2}\right)\end{array}$ & - & 0.010 & 0.026 & 0.019 \\
\hline & & \multirow{5}{*}{$\begin{array}{c}\text { Economic } \\
\text { pressure }\end{array}$} & $\begin{array}{l}\mathrm{X}_{7} \text { Energy consumption per unit GDP } \\
\text { (TCE/10000 yuan) }\end{array}$ & - & 0.092 & 0.015 & 0.046 \\
\hline & & & $\mathrm{X}_{8}$ Industrial wastewater discharge (10kt) & - & 0.071 & 0.025 & 0.043 \\
\hline & & & $\mathrm{X}_{9}$ Industrial smoke emission (10kt) & - & 0.019 & 0.024 & 0.022 \\
\hline & & & $\begin{array}{c}\mathrm{X}_{10} \text { Industrial sulfur dioxide emissions } \\
(10 \mathrm{kt})\end{array}$ & - & 0.035 & 0.034 & 0.035 \\
\hline & & & $\begin{array}{c}X_{11} \text { Production of general industrial solid } \\
\text { waste }(10 \mathrm{kt})\end{array}$ & - & 0.023 & 0.024 & 0.024 \\
\hline & & \multirow{4}{*}{$\begin{array}{c}\text { Social } \\
\text { pressure }\end{array}$} & $\mathrm{X}_{12}$ Urban population density (Person $/ \mathrm{km}^{2}$ ) & - & 0.036 & 0.030 & 0.032 \\
\hline & & & $\begin{array}{l}\mathrm{X}_{13} \text { Per capita housing construction area } \\
\qquad\left(\mathrm{m}^{2}\right)\end{array}$ & - & 0.026 & 0.020 & 0.022 \\
\hline & & & $\begin{array}{c}\mathrm{X}_{14} \text { Urban registered unemployment rate } \\
(\%)\end{array}$ & - & 0.013 & 0.037 & 0.027 \\
\hline & & & $\begin{array}{l}X_{15} \text { Discharge of urban domestic sewage } \\
\left(10 \mathrm{~km}^{3}\right)\end{array}$ & - & 0.005 & 0.024 & 0.017 \\
\hline
\end{tabular}


Table 1. Continued.

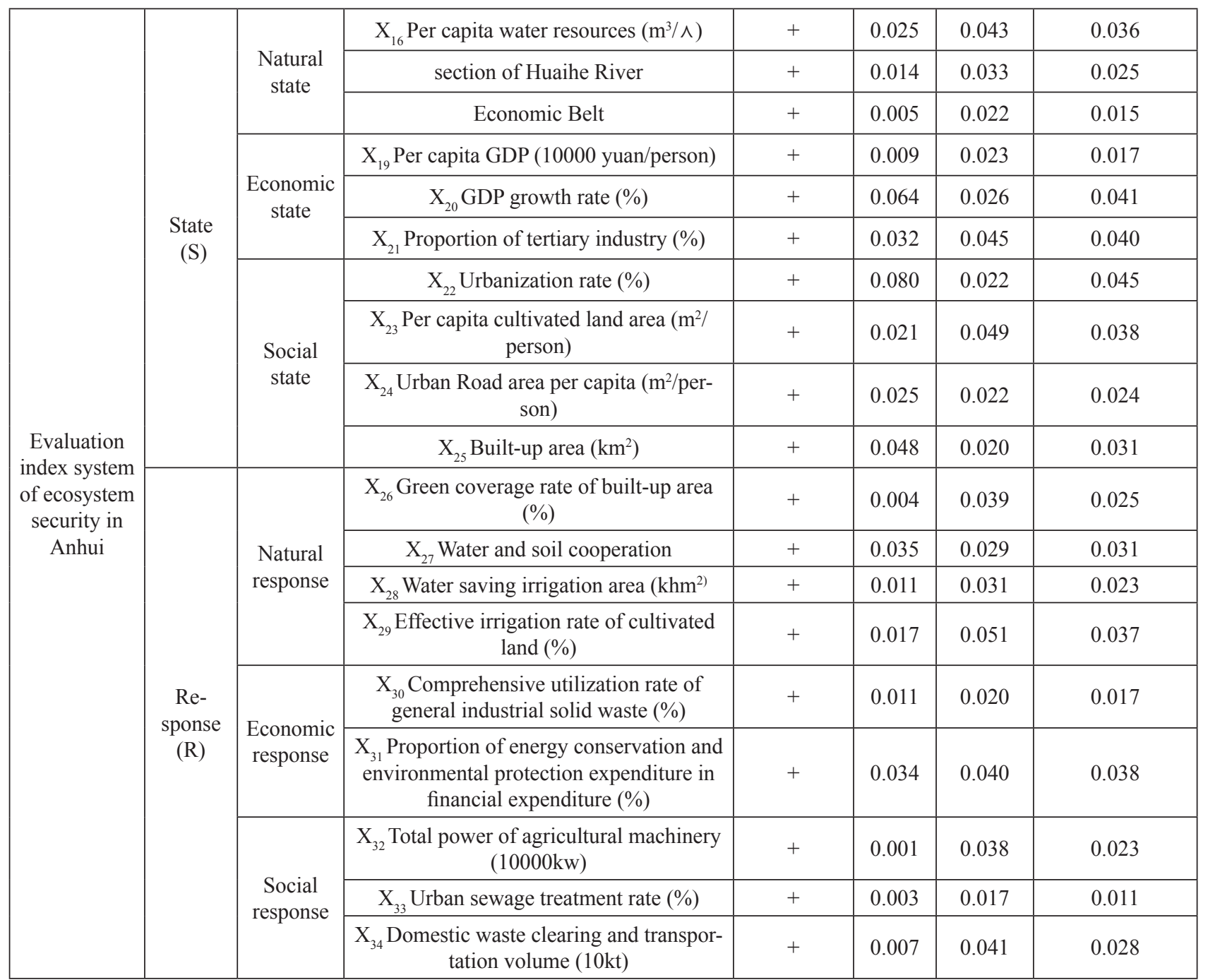

Note: for positive index “+”, the larger the index value is, the better the security status of ecosystem is; for negative indicator "-", the smaller the index value is, the better the security status of ecosystem is.

the other hand, in the light of the natural fracture point method, the ecological system security in Anhui section of Huaihe Economic Belt is divided into four levels: grade IV (very unsafe) $\rightarrow$ grade III (relatively unsafe) $\rightarrow$ grade II (Critical Safety) $\rightarrow$ grade I (very safe) [32]. Finally, the corresponding ecosystem security level was determined. The evaluation results are shown in Table 2.

(1) Overall assessment of ecosystem security

Combined with Table 2, it can be seen that the comprehensive ecosystem security level in Anhui section of The Huai River Economic Belt has experienced a cyclic evolution of "descending ascending - descending - ascending" from 2010 to 2018, and the overall change presented a "W" -shaped curve. Within the study period, firstly, the correlation degree of ecosystem security level increased rapidly, and then decreased slightly, that was, the correlation degree of ecosystem security level raised from the lowest point in 2010 to the second in 2018. This study shows that the level of ecosystem security has been improved and has been out of the lowest level. Furthermore, the average level of correlation between grade II and grade III of ecosystem security was relatively high, which indicated a common state of ecosystem security. Within the time limit of the study, the change of their rank correlation degree was more tortuous, but the numerical fluctuation was not large. In the end, the rank of grade II association increase to the first, while that of grade III was decreasing; On the other hand, the correlation degree of grade IV ecosystem security fluctuated in a "W" pattern, and the overall decline was the largest.

In the PSR model, the change trend of ecosystem security timing sequence of Pressure-State-Response also presents a cyclical trend of "down-up-downdown-up-down" (Fig. 2). Among them, the average correlation degree of response was the highest. The average correlation level of pressure was much higher than the comprehensive correlation level before 2014, 
Table 2. Calculation results of grade correlation degree.

\begin{tabular}{|c|c|c|c|c|}
\hline Year & $\begin{array}{c}\text { Pressure } \\
\text { (I, II, III, IV) }\end{array}$ & $\begin{array}{c}\text { State } \\
\text { (I, II, III, IV) }\end{array}$ & $\begin{array}{c}\text { Response } \\
\text { (I, II, III, IV) }\end{array}$ & $\begin{array}{c}\text { Comprehensive } \\
\text { (I, II, III, IV) }\end{array}$ \\
\hline 2010 & $(0.153,0.207, \mathbf{0 . 5 6 4}, 0.418)$ & $(0.129,0.359,0.409, \mathbf{0 . 4 3 7})$ & $(0.114,0.271,0.511, \mathbf{0 . 6 1 2})$ & $(0.133,0.287,0.453, \mathbf{0 . 5 3 9})$ \\
\hline 2011 & $(0.227,0.358, \mathbf{0 . 4 9 7}, 0.312)$ & $(0.195,0.379,0.391, \mathbf{0 . 4 0 4})$ & $(0.207,0.415,0.442, \mathbf{0 . 5 2 5})$ & $(0.212,0.384,0.433, \mathbf{0 . 4 2 3})$ \\
\hline 2012 & $(0.235, \mathbf{0 . 5 0 3}, 0.481,0.491)$ & $(0.246,0.332, \mathbf{0 . 4 6 2}, 0.324)$ & $(0.252,0.409, \mathbf{0 . 5 4 7}, 0.298)$ & $(0.241,0.429, \mathbf{0 . 5 0 1 ,} 0.347)$ \\
\hline 2013 & $(0.182,0.402,0.426, \mathbf{0 . 5 4 4})$ & $(0.255,0.378, \mathbf{0 . 4 1 8}, 0.354)$ & $(0.335,0.458, \mathbf{0 . 5 0 7}, 0.212)$ & $(0.261,0.417,0.405, \mathbf{0 . 4 5 9})$ \\
\hline 2014 & $(0.201,0.348,0.432, \mathbf{0 . 4 4 3})$ & $(0.247,0.387, \mathbf{0 . 4 0 2}, 0.334)$ & $(0.384, \mathbf{0 . 5 3 4}, 0.498,0.343)$ & $(0.285,0.434, \mathbf{0 . 4 4 5}, 0.352)$ \\
\hline 2015 & $(0.229,0.357, \mathbf{0 . 4 0 8}, 0.231)$ & $(0.381,0.327, \mathbf{0 . 3 9 9}, 0.146)$ & $(0.471, \mathbf{0 . 5 5 4}, 0.461,0.292)$ & $(0.426, \mathbf{0 . 4 9 1 ,}, 0.424,0.203)$ \\
\hline 2016 & $(0.363, \mathbf{0 . 3 7 7}, 0.271,0.193)$ & $(\mathbf{0 . 4 1 8}, 0.383,0.274,0.271)$ & $(\mathbf{0 . 4 9 2}, 0.362,0.358,0.172)$ & $(\mathbf{0 . 4 2 6}, 0.368,0.316,0.198)$ \\
\hline 2017 & $(0.209, \mathbf{0 . 3 8 1}, 0.378,0.361)$ & $(0.357, \mathbf{0 . 3 7 4}, 0.365,0.214)$ & $\mathbf{( 0 . 5 8 2 , 0 . 5 7 9 , 0 . 4 2 8 , 0 . 1 6 4 )}$ & $(0.396, \mathbf{0 . 4 8 6}, 0.391,0.227)$ \\
\hline 2018 & $(0.267,0.374, \mathbf{0 . 4 1 2}, 0.367)$ & $(0.371, \mathbf{0 . 3 8 8}, 0.355,0.197)$ & $(\mathbf{0 . 5 6 3}, 0.554,0.349,0.197)$ & $(0.394, \mathbf{0 . 4 7 9}, 0.367,0.288)$ \\
\hline
\end{tabular}

and then decreased year by year after 2014. The average correlation degree of states was the lowest. This was consistent with China's spatial pattern of attaching great importance to ecological civilization construction, adhering to resource conservation and ecological environment protection, and has achieved remarkable results [33].

(2) Temporal characteristics of ecosystem security

From the perspective of the evolution trend of ecosystem security in the pressure layer, from 2010 to 2018 , the ecosystem security level of the standard layer first decreased and then increased, and following decreased and increased again, showing a "W" type decline and fluctuation trend, which has experienced three levels of grade IV, III and II. In 2010 and 2011, the ecosystem security of the pressure criterion layer in Anhui belonged to grade III, but the correlation degree of grade III was decreasing year by year, which indicated that the ecosystem security pressure might be separated from this level in some period of the next year, and the ecosystem pressure would be reduced. In 2012, the security level of stress ecosystem jumped to level II, and the correlation between stress ecological security and level II reached to the peak. In 2013 and 2014, the security level of stress ecosystem has decreased from grade II to grade IV, and improved from 2015 to 2017, and maintained at level II in 2016 and 2017. The correlation degree of pressure criterion level corresponding to level II decreased slightly from 2017 to 2018, and then fell to level III in 2018.

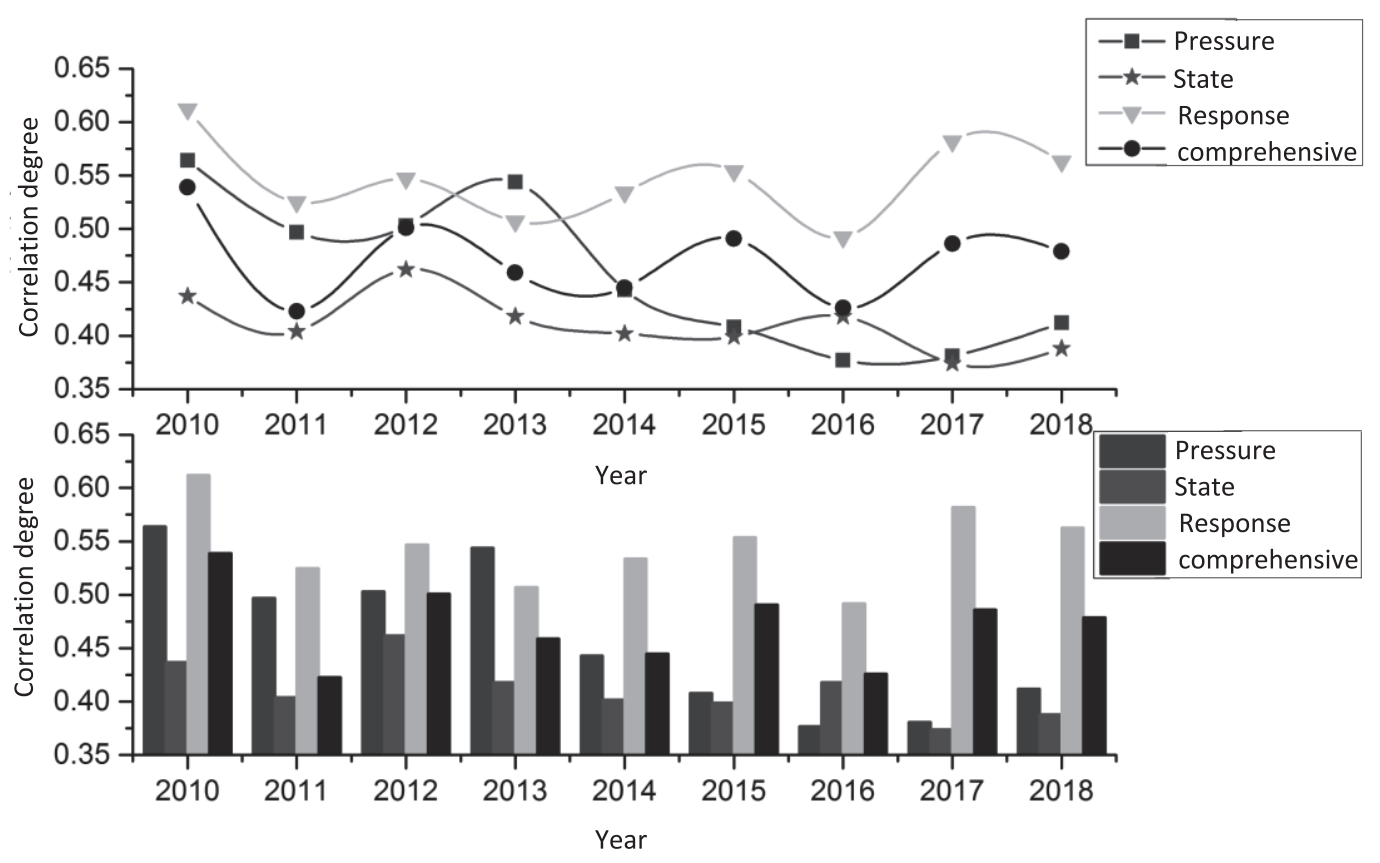

Fig. 2 Changes in the correlation degree of ecosystem security levels. 

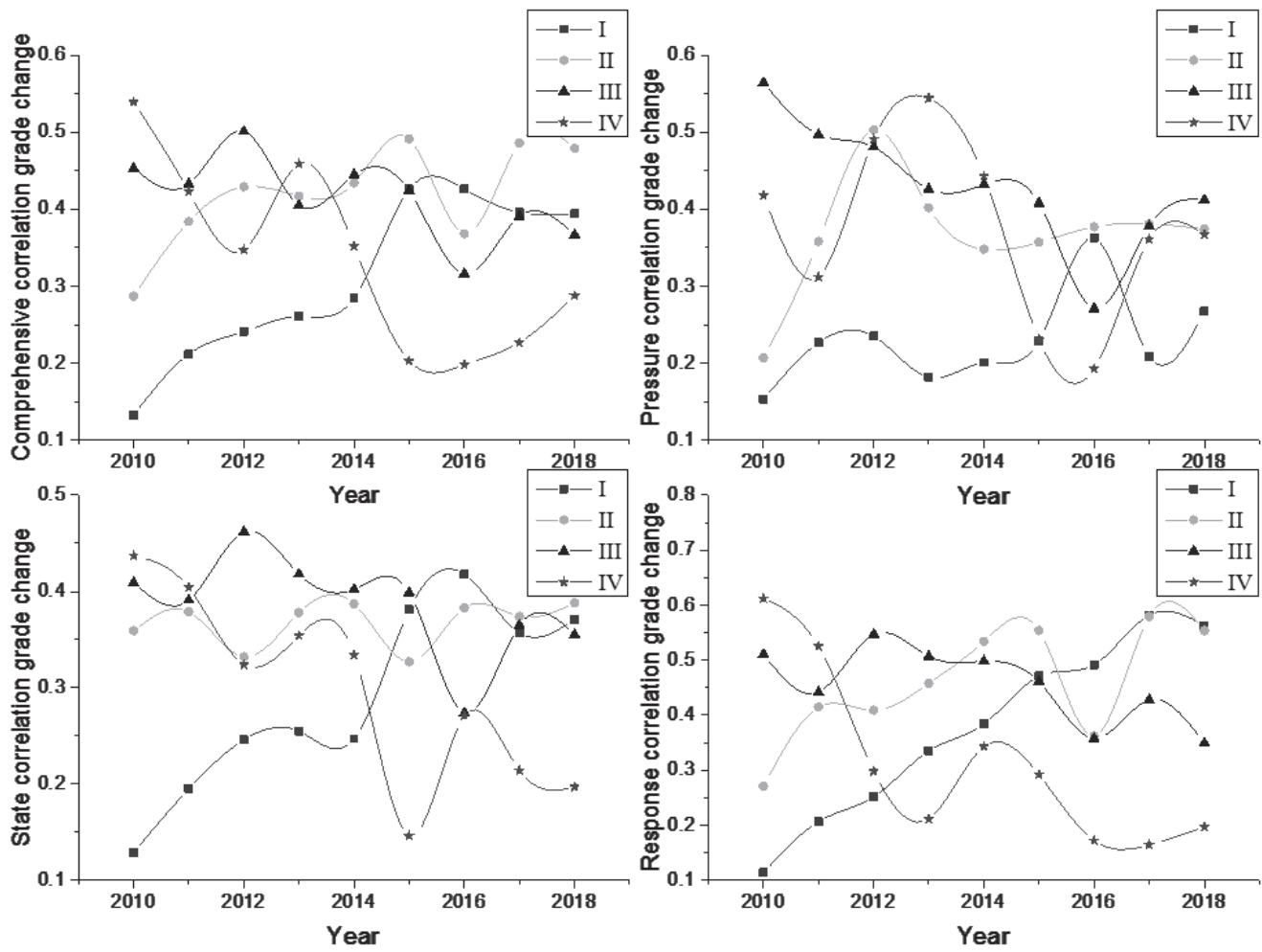

Fig. 3 Temporal variation of ecosystem security grade correlation degree.

In the light of the evolution trend of the state level ecosystem security, the evolution trend of the state criterion level ecosystem security can be divided into two stages: the first stage was 2010-2016, in which the level of ecosystem security was in a slow rising period, from grade IV in 2010 to grade I in 2016. During this period, the trend line of correlation degree corresponding to grade I of state criterion layer showed an upward trend, and subsequently reached the peak in 2016. The trend line of correlation degree of the other three levels was highly volatile, and the correlation degree obviously decreased compared with 2010 and 2016, which indicated that the ecological security level of the state criterion layer has a good trend. The second stage was from 2016 to 2018. In this stage, the level of ecosystem security descended from grade I to grade II. The correlation degree of grade II was the largest, while the correlation degree of grade IV was the lowest and even showed a downward trend, which adequately indicated that the state of ecological security was good in this period.

From the perspective of the evolution trend of ecosystem security in response layer, the level of ecosystem security in response criterion layer increased year by year, especially after 2013, the level increased fastest, and it was at level I for three consecutive years from 2016 to 2018. Among them, the level I correlation degree has increased from the lowest point in 2010 to the highest point in 2018, and the fourth level correlation degree also decreased from the maximum value in the early stage of the study to the minimum value, which shows that people have realized the importance of ecosystem security and pay more and more attention to ecological security. Response activities have been made to maintain ecosystem security from three levels of nature, economy and society. The improvement of index values such as green coverage rate of built-up area, proportion of energy conservation and environmental protection expenditure in financial expenditure, and urban sewage treatment rate has played a role in promoting the rise of ecosystem security level in response to criteria.

(3) Spatial characteristics of ecosystem security

Considering that 2010 is the end of the $11^{\text {th }}$ five-year plan, 2015 is the end of the $12^{\text {th }}$ five-year plan, and 2018 is the first year to implement the spirit of the $19^{\text {th }}$ National Congress of the Communist Party of China, and it is also a key year for the implementation of the $13^{\text {th }}$ five-year plan. Therefore, this paper selects 2010, 2015 and 2018 as typical years to compare and analyze the differences of ecosystem security level of eight cities in Anhui section of Huaihe River Economic Belt in different typical years. The spatial diversity of ecosystem security in eight cities in each typical year is shown in Fig. 4. The comprehensive correlation degree of eight cities in Anhui section of Huaihe River Economic Belt is classified by natural fracture point classification method. The smaller the comprehensive correlation index is, the more prominent the problem of ecosystem security is and the more uncoordinated the development of ecological security is. 

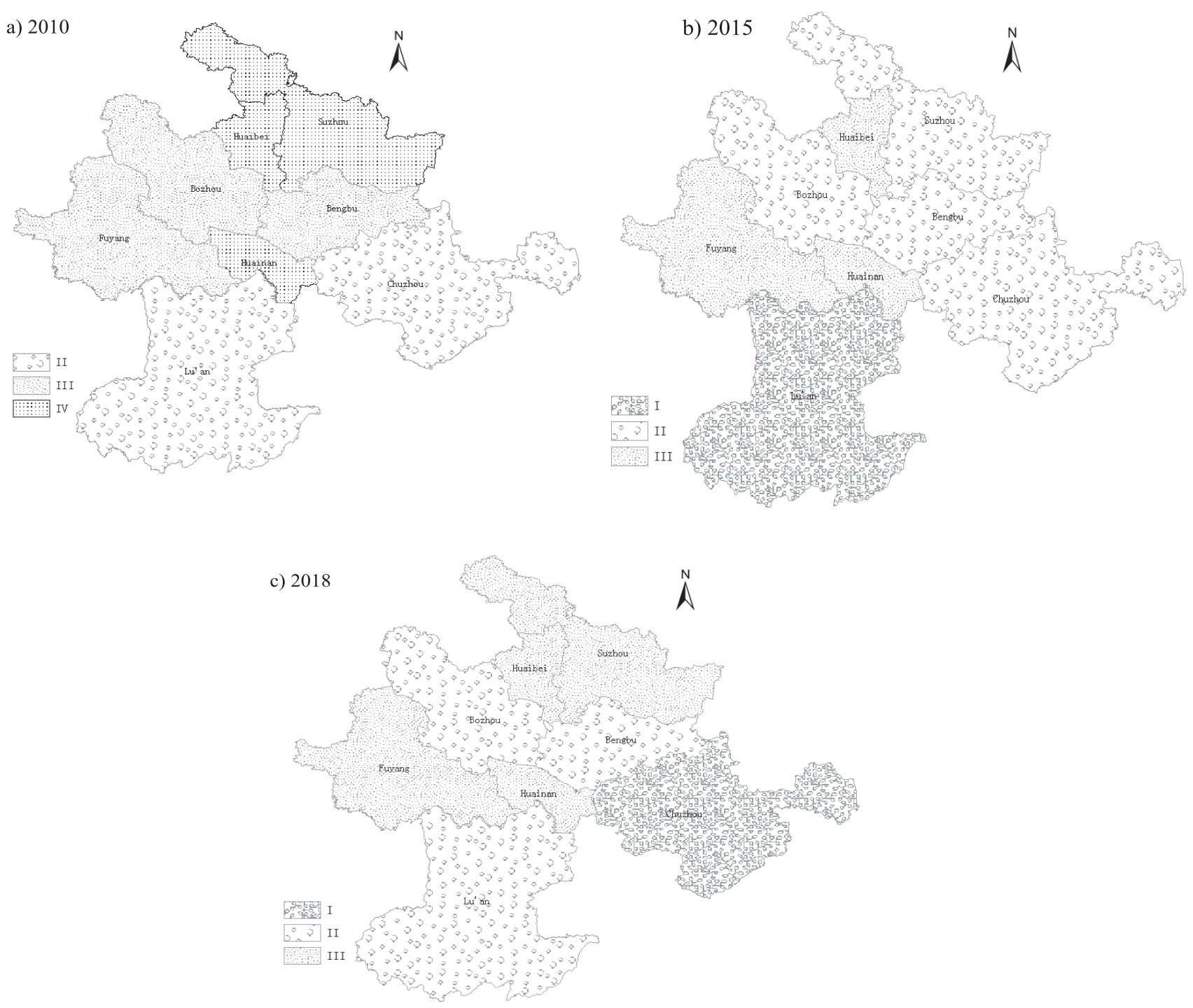

Fig. 4 Spatial variation of integrated ecosystem security levels in various cities in Anhui Section a) 2010, b) 2015, c) 2018.

It can be seen from Fig. 4, the ecological security level of Suzhou, Huaibei and Huainan in 2010, Fuyang, Huaibei and Huainan in 2015 and Fuyang, Suzhou, Huaibei and Huainan in 2018 were relatively low, and the coordination and consistency of production activities and ecological protection needed to be improved. On the whole, the overall level of ecosystem security of eight cities in Anhui section of Huaihe River Economic Belt in 2010 was quite different, and the uneven situation was more significant. In 2015 and 2018, the ecological security level of Fuyang, Suzhou, Huainan and Huaibei was relatively backward, and the overall level was at level III. Through the data analysis, it can be seen that the cities with backward ecological security level were relatively the same in different typical years, which indicated that the ecological system security level of each city fluctuates little. The government should continue to strengthen the unified supervision, carry out the urban greening promotion project and forest growth project, and eventually ensure the coordinated development of the ecological system of Huaihe River Economic Belt.

\section{Obstacle Factor Diagnosis}

On the basis of the resistance diagnosis model, the resistance values of the ecological system safety indexes of various cities in Anhui section of the Huaihe River Economic Belt in 2018 were calculated. In view of the large number of indicator layer factors, only the top 5 indicators with the largest resistance value (cumulative resistance value exceeding $40 \%$ ) were selected, which was the main ecological obstacle factors affecting the ecosystem security in Anhui section of Huaihe River Economic Belt (Table 3).

In the light of Table 3, we took 2018 as the sample for analysis. The results proved that the obstacle factors of ecosystem security in Huaibei were the proportion of energy conservation and environmental protection expenditure in fiscal expenditure, the greening 
Tab. 3 Main obstacle factors and resistance values of ecosystem security in eight cities of Anhui Section in 2018

\begin{tabular}{|c|c|c|c|c|c|}
\hline \multirow{2}{*}{ City } & \multicolumn{5}{|c|}{ Obstacle factors and resistance values } \\
\cline { 2 - 6 } & 1 & 2 & 3 & 4 & 5 \\
\hline Huaibei & $\mathrm{X} 31(0.153)$ & $\mathrm{X} 26(0.099)$ & $\mathrm{X} 12(0.094)$ & $\mathrm{X} 5(0.088)$ & $\mathrm{X} 17(0.084)$ \\
\hline Bozhou & $\mathrm{X} 12(0.103)$ & $\mathrm{X} 15(0.096)$ & $\mathrm{X} 8(0.088)$ & $\mathrm{X} 9(0.072)$ & $\mathrm{X} 20(0.068)$ \\
\hline Suzhou & $\mathrm{X} 11(0.137)$ & $\mathrm{X} 6(0.126)$ & $\mathrm{X} 18(0.124)$ & $\mathrm{X} 4(0.091)$ & $\mathrm{X} 22(0.082)$ \\
\hline Bengbu & $\mathrm{X} 22(0.125)$ & $\mathrm{X} 16(0.100)$ & $\mathrm{X} 7(0.095)$ & $\mathrm{X} 13(0.073)$ & $\mathrm{X} 27(0.070)$ \\
\hline Fuyang & $\mathrm{X} 1(0.132)$ & $\mathrm{X} 4(0.103)$ & $\mathrm{X} 20(0.095)$ & $\mathrm{X} 14(0.094)$ & $\mathrm{X} 29(0.086)$ \\
\hline Huainan & $\mathrm{X} 24(0.147)$ & $\mathrm{X} 8(0.141)$ & $\mathrm{X} 15(0.098)$ & $\mathrm{X} 17(0.090)$ & $\mathrm{X} 26(0.086)$ \\
\hline Chuzhou & $\mathrm{X} 2(0.139)$ & $\mathrm{X} 13(0.097)$ & $\mathrm{X} 21(0.095)$ & $\mathrm{X} 9(0.092)$ & $\mathrm{X} 27(0.087)$ \\
\hline Lu'an & $\mathrm{X} 20(0.127)$ & $\mathrm{X} 24(0.099)$ & $\mathrm{X} 19(0.099)$ & $\mathrm{X} 8(0.096)$ & $\mathrm{X} 29(0.081)$ \\
\hline
\end{tabular}

coverage rate of built-up area, urban population density, pesticide application amount per unit cultivated area, and per capita park green space area. Secondly, the obstacle factors of ecosystem security in Bozhou were population density, urban domestic sewage discharge, industrial wastewater discharge, industrial dust emission and GDP growth rate. Thirdly, the barriers to ecosystem security in Suzhou were the production of general industrial solid waste, the amount of plastic film used per unit cultivated land, forest coverage rate, fertilizer application amount per unit cultivated area, and urbanization rate. Fourthly, the obstacle factors of ecosystem security in Bengbu were urbanization rate, per capita water resources, energy consumption per unit GDP, per capita housing area and water and soil CO regulation. Fifthly, the obstacle factors of ecosystem security in Fuyang were natural population growth rate, fertilizer application amount per unit cultivated land area, GDP growth rate, urban registered unemployment rate and effective irrigation rate of cultivated land. Sixly, the obstacle factors of ecosystem security in Huainan City were urban road area per capita, industrial wastewater discharge, urban domestic sewage discharge, per capita park green space area and green coverage rate of built-up area. Seventhly, the obstacle factors of ecosystem security in Chuzhou were daily water consumption per capita, housing construction area per capita, proportion of tertiary industry, industrial smoke and dust emission, water and soil $\mathrm{CO}$ regulation. Eighthly, the obstacle factors of ecosystem security in Lu'an City were GDP growth rate, per capita urban road area, per capita GDP, industrial wastewater discharge and effective irrigation rate of cultivated land.

\section{Resistance Analysis and Discussion}

According to the resistance value of the main obstacle factors, the main obstacle factors with the resistance value of ecosystem security exceeding 0.100 in Anhui Province in 2018 were different. 1) The main obstacle factor of Huaibei was the proportion of energy conservation and environmental protection expenditure in fiscal expenditure (0.153). Hence, increasing investment in energy conservation and environmental protection plays an important role in improving ecosystem security. 2) The main obstacle factor of Bozhou was urban population density $(0.103)$. Therefore, the increase of urban population density leads to the sharp increase of resource demand and the increase of ecosystem load. 3) The main obstacle factors in Suzhou were the amount of general industrial solid waste (0.137), the amount of plastic film used per unit cultivated area $(0.126)$ and the forest coverage rate $(0.124)$. The reason is that the utilization rate of general industrial solid waste is low, which leads to a large amount of industrial solid waste and threatens the safety of ecosystem. Since the 13th five-year plan, with the promotion of ecological agriculture and the implementation of land protection plan, the pressure of farmland plastic film use was easing, but the pressure was still very large. In addition, due to the unreasonable development of mountain areas, the forest has been cut down excessively, resulting in low forest coverage. 4) The main obstacle factors of Bengbu were urbanization rate $(0.125)$ and per capita water resources $(0.100)$. If the urbanization process was too high or too low, the balance of ecosystem would be affected. The increase of population scale and the decrease of fresh water resources reserve were the main reasons for the shortage of per capita water resources; water pollution, backward industrial water circulation technology and over exploitation of groundwater will hinder the improvement of ecosystem security level. 5) The main obstacle factors of Fuyang were natural population growth rate $(0.132)$ and fertilizer application amount per unit cultivated area (0.103). According to the data analysis, in 2018, the number of permanent residents in Fuyang City was huge, ranking the first in the province, which seriously increased the burden of the ecosystem, the implementation of ecological agriculture was not thorough, and the amount of fertilizer applied to cultivated land posed a threat to soil security. 6) The main obstacle factors of Huainan 
were the per capita urban road area $(0.147)$ and the industrial wastewater discharge (0.141). Because Huainan is an important energy city, a large number of coal mining leads to serious ground subsidence, many road sections collapse, and the per capita urban road area decreases, which is the main reason for the ecological system security problems in Huainan City. 7) The main obstacle factor of Chuzhou was daily water consumption per capita (0.139). The main reason was that the problem of water use for residents was closely related to the ecosystem. 8) The main obstacle factor of Lu'an was GDP growth rate (0.127). As we all know, economy is an important support to solve the problem of ecosystem security. The slow economic development of Lu'an City is the primary obstacle factor of ecosystem security.

According to the empirical results, the main factors of ecological security barriers belong to different criterion layers. For Huaibei, the first and second obstacle factors come from the response layer, the third and fourth obstacle factors come from the pressure layer, and the fifth obstacle factor comes from the state layer. For Bozhou, the first four obstacle factors come from the pressure layer, and the fifth obstacle factor comes from the state layer. For Suzhou, the first, second and fourth obstacle factors come from the pressure layer, and the third and fifth obstacle factors come from the state layer. For Bengbu, the first and second obstacle factors come from the state level, the third and fourth obstacle factors come from the pressure layer, and the fifth obstacle factor comes from the response layer. For Fuyang, the first, second and fourth obstacle factors come from the pressure layer, the third obstacle factor comes from the state layer, and the fifth obstacle factor comes from the response layer. For Huainan, the first and fourth obstacle factors come from the state layer, the second and third obstacle factors come from the pressure layer, and the fifth obstacle factor comes from the response layer. For Chuzhou, the first, second and fourth obstacle factors come from the pressure layer, the third obstacle factor comes from the state layer, and the fifth obstacle factor comes from the response layer. For Lu'an, the first, second and third obstacle factors come from the state layer, the fourth obstacle factor comes from the pressure layer, and the fifth obstacle factor comes from the response layer.

In conclusion, most of the obstacle factors in the eight cities come from the pressure criterion layer, which indicates that the pressure layer index is the key factor limiting the improvement of ecosystem security level. Among them, more than half of the main obstacle factors in Bozhou, Suzhou, Fuyang and Chuzhou come from the pressure layer. Therefore, these four cities need to enhance the anti pressure ability of the ecosystem, focus on the development of the pressure layer indicators, and regulate the safety level in real time. The main obstacle factors of Lu'an mainly come from the state level, and the only pressure index GDP growth rate is the primary obstacle factor, which conforms to the actual situation that Lu'an GDP ranking is in the middle and lower reaches of Anhui province's GDP ranking in recent years, and the economic level is not good. Lu'an, as the sub central city of Hefei Economic Circle and the central city of Dabie Mountain Area, has a unique strategic position and huge economic development potential. Therefore, Lu'an should seize the opportunity to promote economic development rapidly, and its ecosystem security status index will certainly fall out of the main obstacle factor sequence. The main obstacle factors in Huaibei, Bengbu and Huainan are more evenly distributed in the pressure, state and response criteria. Among them, there are many response layer indicators in Huaibei, which hinder the improvement of ecosystem security level. The reason is that the green coverage area of Huaibei urban built-up area is small, and the investment in energy conservation and environmental protection is insufficient.

\section{Conclusions}

From 2010 to 2018, the ecological security level of Anhui section of Huaihe River Economic Belt experienced the evolution trend of "decline rise decline rise", and the overall change showed a "W" curve, and the level of ecosystem security was improved. The results showed that the ecosystem security level of the pressure layer fluctuated in a "W" shape, the state layer showed an inverted "V" pattern, and the response layer showed an upward trend year by year. Among them, the change trend of the pressure layer was similar to that of the comprehensive ecosystem security. It can be seen that the pressure criterion layer was the key to affect the ecosystem security.

According to the resistance diagnosis results, the main obstacle factors of ecosystem security in Anhui section of Huaihe River Economic Belt mainly come from the pressure layer indicators. The urban population density, the proportion of energy conservation and environmental protection expenditure in the financial expenditure, the per capita urban road area, and the industrial wastewater discharge are the larger resistance factors. Therefore, it is necessary to implement the strictest control measures for the ecological red line control area in Anhui section of Huaihe ecological economic belt, and prohibit all forms of development and construction activities.

In order to improve the level of ecosystem security in Anhui section of Huaihe River Economic Belt, we should not only focus on the two subsystems of pressure and response, but also take into account the stable coordination among the subsystems of PSR. In addition, the relevant departments should reasonably optimize the ecological structure in Anhui section of Huaihe River Economic Belt. For resource-based cities Huainan and Huaibei, it is necessary to adjust and optimize their industrial structure, actively develop 
comprehensive resource recycling industries such as coal gangue, fly ash, gas, agricultural waste and animal manure, and vigorously develop circular economy. For Fuyang, Suzhou, Bozhou and other large agricultural cities, it is necessary to implement the requirements of clear water, green shore, excellent industry and urban ecological network construction, reasonably develop land resources, actively promote the construction of ecological agriculture, and improve the level of agricultural mechanization.

\section{Acknowledgments}

This work was supported by the following programs: 1. The National Natural Science Foundation of China with the title "Evaluation of Coal Miners' Safety Behavioral Ability and Its Dynamic Prewarning under the Interaction between Individuals and Environment" (NO. 51574010). 2. The National Natural Science Foundation of China with the title "Action recognition based on heterogeneous features fusion in multi-sensors network" (NO. 61873004). 3. Independent Project of State Key Laboratory of Mining Response and Disaster Prevention and Control in Deep Coal Mines with the title "Research on underground dust monitoring and intelligent early warning system" (NO. SKLMRDPC20ZZ12). 4. Anhui Province Philosophy and Social Science Planning Project with the title "Research on coupling and coordinated development of industrial transformation and upgrading and ecological environment in Huaihe River Economic Belt" (NO. AHSKY2019D026). 5. Key Projects of Humanities and Social Sciences in Anhui with the title "Research on safety early warning system of underground support deformation monitoring based on laser intrusion detector" (NO. SK2020A0213).

\section{Conflict of Interest}

The authors declare no conflict of interest.

\section{References}

1. The Website of the Central People's Government of the PRC. The 19th Congress of the Communist Party of China. Available online: http://cpc.people.com.cn/19th/ n1/2017/1022/c414305-29601176.html (accessed on 20- 112020).

2. The Website of the Central People's Government of the PRC. Central economic work conference in 2019. Available online: http://www.gov.cn/xinwen/2019-12/12/ content_5460670.html (accessed on 20-11-2020).

3. Ministry of Ecological Environment. Guidance on overall planning for epidemic prevention and control, economic and social development, ecological and environmental protection. Available online: http://www.mee.gov.cn/ xxgk2018/xxgk/xxgk03/202003/t20200304_767281.html (accessed on 20-11-2020).
4. THOMAS M.Q., RICHARD W.H., WENDEL J.H. Estimating ecological integrity in the interior Columbia River basin. Forest Ecology and Management. 153, 161, 2001.

5. WHITFORD W.G., RAPPORT D.J., DESOYZA A.G. Using resistance and resilience measurements for fitness tests in ecosystem health. Journal of Environmental Management. 57 (1), 21, 1999.

6. ZHANG C., LI J., ZHOU Z.X., SUN Y.J. Application of ecosystem service flows model in water security assessment: A case study in Weihe River Basin, China. Ecological Indicators. 120, 2021.

7. PIERI C., DUMANSKI J., HAMBLIN A., YOUNG A. Land Quality Indicators. World Bank-Discussion Papers, 81 (2), 81, 1995.

8. DE LANGE H.J., SALA S., VIGHI M., FABER J.H. Ecological vulnerability in risk assessment - A review and perspectives. Science of the Total Environment, 408 (18), 3871, 2010

9. MALCZEWSKI J. Ordered weighted averaging with fuzzy quantifiers: GIS-based multicriteria evaluation for land-use suitability analysis. International Journal of Applied Earth Observation and Geoinformation. 8 (4), 1, 2006.

10. BARNTHOUSE L.W., SUTER G.W. Use manual for ecological risk assessment. Washington D.C.: ORNL, March, 1986

11. LAI X.D., XIAO Z.H. A research on urban eco-security evaluation and analysis: complex system's brittle structure model. Environmental Science and Pollution Research. 27 (20), 24914, 2020.

12. YANG Y., CAI Z.X. Ecological security assessment of the Guanzhong Plain urban agglomeration based on an adapted ecological footprint model. Journal of Cleaner Production. 260, 2020.

13. LI B., SHI P.J., JIN S.T. Research on Ecological Risk Assessment of Vegetation Ecosystem in Shiyang River Basin. Bulletin of Soil and Water Conservation. 33 (1), 201, 2013.

14. WANG J.W., MENG J.J. Ecological Risk Assessment and Management of Floods and Droughts in the Li River Basin. Tropical Geography. 34 (3), 366, 2014.

15. GONG J., ZHAO C.X., XIE Y.C., GAO Y.J. Ecological risk assessment and its management of Bailongjiang watershed, southern Gansu based on landscape pattern. Chinese Journal of Applied Ecology. 25 (7), 2041, 2014.

16. SONG T., LI D.Q., ZHANG L.B., WANG G.Z., GAO Y.N., YANG C.Y., FENG C.Y., MA H. Importance Evaluation of Ecosystem Services and Construction of Ecological Security Pattern in Qinba Mountain Area. Strategic Study of CAE. 22 (01), 64-72, 2020.

17. JIANG C.J., LI Y.X., WANNG Y.M. Research on safety evaluation and resistance of land use ecosystem in China section of "Silk Road Economic Belt". Journal of Earth Environment. 9 (02), 200, 2018.

18. JIN F.J., MA L., XU D. Environmental stress and optimized path of industrial development in the Yellow River Basin. Resources Science. 42 (01), 127, 2020.

19. SUN C.J., LI X.M., ZHANG W.Q., LI X.G. Evolution of Ecological Security in the Tableland Region of the Chinese Loess Plateau Using a Remote-Sensing-Based Index. Sustainability. 12 (8), 2020.

20. PAN X.P., ZHOU J.S., SHA J.H., XIE C.Y. Evaluation on the development and construction of national mining economic zone in Anhui province. China's mining industry. 23 (09), 53, 2014. 
21. LIU Y.J. Study on optimization of modern industrial system in accepting industry transfer in central and western regions--taking Anhui province as an example to undertake industry transfer in the Yangtze River delta region. East China economic management. 27, 28, 2013.

22. HE G., YANG J.W., BAO K.Y., ZHOU Q.T. Analysis for the spatial correlation and the impact of the newly urbanized trend on the regional eco-environment quality. Journal of Safety and Environment. 20 (05), 1958, 2020.

23. YAN J., CUI R.P. Study on Spatial-temporal Differentiation and Convergence of Tourism Economy in the Huaihe River Eco-economic Belt. Areal Research and Development. 39 (04), 91, 2020.

24. CAO Y.H., XIA Y.X., MAO G.X., CAI A.N., LIU C.M. Research on Regional Development Difference and Collaborative Development Strategy of the Huaihe River Eco-economic Belt. Economic Geography. 39 (09), 213, 2019.

25. GAN L.X., CHENG X.D., WANG C. On the evaluation for the pilotage navigation environment risks based on the cloud matter-element model. Journal of Safety and Environment. 18 (02), 418, 2018.

26. HE G., JIN L., ZHU Y.N. Ecological Security Evaluation and Ecological Resistance Analysis of Hefei City Based on Cloud Matter Element. Areal Research and Development. 39 (06), 171, 2020.

27. LI H.H., MA T.H., WANG K., TAN M., QU J.F. Construction of Ecological Security Pattern in Northern Peixian Based on MCR and SPCA. Journal of Ecology and Rural Environment. 36 (08), 1036, 2020.
28. YANG Z.G., JIANG Z.Y., GUO C.X., YANG X.J., XU X.J., LI X., HU Z.M., ZHOU H.Y. Construction of ecological network using morphological spatial pattern analysis and minimal cumulative resistance models in Guangzhou City, China. Chinese Journal of Applied Ecology. 29 (10), 3367, 2018.

29. WANG Y., DONG X.G., WANG H.F., ZHAO C.J., ZHU J.W. Evaluation and obstacle factor diagnosis of land ecological security in Zhengzhou based on PSR-TOPSIS model. Journal of Henan Agricultural University. 54 (05), 845, 2020.

30. CAI X., YANG Y., LI P.S., LI Z., GOU Y.P., LI Z. PSR-NES coupling model based land ecological status comprehensive assessment. Journal of Northwest University (Natural Science Edition). 50 (04), 685, 2020.

31. GAO Q.Z., XU H.M., KANG M.Y., YANG J., SUN L., ZHAO Y.L. Comprehensive Evaluation on Ecological Security in the Soft Rock Area in Middle Reaches of the Yellow River: A Case Study in Changchuan Watershed, China. Resources Science. 2, 132, 2006.

32. XUE L.Q., WANG J., WEI G.H. Dynamic evaluation of the ecological vulnerability based on PSR modeling for the Tarim River Basin in Xinjiang. Journal of Hohai University (Natural Sciences). 47 (01), 13, 2019.

33. WAN X.L., ZHOU Y.Y., WANG X.L., YANG L.R. The International Communication of the 15th Meeting of the Conference of the Parties to the Convention on Biological Diversity (COP15) and Ecological Civilization. Environmental Protection. 48 (22), 55, 2020. 